\title{
PENGEMBANGAN MODUL KIMIA BERBASIS POE (PREDICT, OBSERVE, AND EXPLAIN) PADA MATERI SIFAT KOLIGATIF LARUTAN SEBAGAI SUMBER BELAJAR PESERTA DIDIK KELAS XII SMA/MA

\author{
Roza Novia Putri*, Erviyenni*, Betty Holiwarni *
} \\ Email: *rozaputrinovia@gmail.com,*erviyenni@gmail.com,*holi_warni@yahoo.com Phone: 082391101407 \\ Program Studi Pendidikan Kimia \\ Fakultas Keguruan Dan Ilmu Pendidikan \\ Universitas Riau
}

\begin{abstract}
The development of POE-based chemical modules on the colligative properties of the solution aims to obtain a valid chemical module based on the content feasibility, language, graphics, and presentation aspects. The research method of developing chemical module using 4-D model consists of four stages: Define (define) stage, Design stage, Development stage and Desseminate stage. In this research only carried out until the development stage. Data collection techniques are using validation sheets given to two validators aim to assess the chemical modules that have been developed. The result of the research shows the acquisition of feasibility aspect of content $97.01 \% ; 100 \%$ language feasibility aspect; aspect of $97.91 \%$ feasibility of aquality; and the feasibility aspect of $98.21 \%$ presentation. The average of validation score of all POE based chemical modules on the colligative properties of the solution is $96.7975 \%$ with very good category (very valid). Valid chemical modules are then tested to respondents. The respondents were limited to 4 chemistry teachers from SMA N 5 Pekanbaru and SMA N 8 Pekanbaru and 20 students from SMA N 5 Pekanbaru and SMA N 8 Pekanbaru. Analysis of user response data based on teachers 'sheets and learners' scored $93.667 \%$ and $89.53 \%$. The overall avarege validation and limited validity testing scores stated that chemical modules based on POE can be used in the learning process.
\end{abstract}

Keywords: Module, POE, Colligative Properties of Solution 


\begin{abstract}
Abstrak
Pengembangan modul kimia berbasis POE pada materi sifat koligatif larutan bertujuan untuk memperoleh modul kimia yang valid berdasarkan aspek kelayakan isi, bahasa, kegrafikan, dan penyajian. Metode penelitian pengembangan modul kimia menggunakan model 4-D, terdiri atas empat tahapan yaitu tahap Define (pendefenisian), tahap Design (perancangan), tahap Development (pengembangan) dan tahap Desseminate (penyebaran). Pada penelitian ini hanya dilakukan hingga tahap pengembangan. Teknik pengumpulan data menggunakan lembar validasi yang diberikan kepada dua orang validator bertujuan untuk menilai modul kimia yang telah dikembangkan. Hasil penelitian menunjukkan perolehan skor aspek kelayakan isi 97,01\% ; aspek kelayakan bahasa $100 \%$; aspek kelayakan kegrafikan 97,91\% ; dan aspek kelayakan penyajian 98,21 \%. Jadi skor rata-rata validasi keseluruhan modul kimia berbasis POE pada materi sifat koligatif larutan yaitu 96,7975\% dengan kategori sangat baik (sangat valid). Modul kimia yang telah valid kemudian diuji cobakan kepada responden. Responden uji coba terbatas terdiri atas 4 orang guru kimia dari SMA N 5 Pekanbaru dan SMA N 8 Pekanbaru serta 20 orang peserta didik dari SMA N 5 Pekanbaru dan SMA N 8 Pekanbaru. Analisis data tanggapan pengguna berdasarkan lembar guru dan peserta didik memperoleh skor 93,667\%. dan 89,53\%. Skor rata-rata validasi keseluruhan dan uji coba terbatas menyatakan Modul Kimia berbasis POE dapat digunakan dalam proses pembelajaran.
\end{abstract}

Kata Kunci : Modul, POE, Sifat Koligatif Larutan

\title{
PENDAHULUAN
}

Pembelajaran di SMA cenderung belum menekankan pada pemberian pengalaman belajar melalui penggunaan dan pengembangan keterampilan proses. Sebagai akibatnya peserta didik kesulitan mengaitkan antara materi pembelajaran kimia dengan objek atau fenomena-fenomena yang bermanfaat di sekitar kehidupan manusia. Padahal, arti sebenarnya dari belajar kimia adalah upaya untuk mengetahui berbagai fenomena atau gejala alam agar mendapatkan sesuatu yang bermanfaat bagi kehidupan manusia. Paradigma Pendidikan Nasional Abad 21 yang telah dikeluarkan Badan Standar Nasional Pendidikan (BNSP), pembelajaran kimia dituntut untuk tidak lagi berpusat pada guru (teacher-centered), melainkan berpusat pada peserta didik (student- 
centered). Pembelajaran kimia harus menekankan pada keterkaitan antara materi yang dipelajari (konten) dan masalah-masalah yang ada dalam kehidupan nyata (konteks) peserta didik (BNSP, 2010).

Berdasarkan hasil pengamatan peneliti di SMA Negeri 10 Pekanbaru, belum ada modul kimia berbasis model pembelajaran yang sesuai dengan kurikulum 2013 yang dikembangkan oleh guru. Keadaan ini menjadi semakin sulit saat buku teks yang diharapkan mampu menjelaskan konsep penting ada dalam jumlah yang terbatas artinya tidak semua peserta didik dapat memilikiya maka banyak diantara peserta didik yang tidak memahami materi.

Mengatasi masalah di atas maka perlu diberikan solusi berkaitan dengan sarana pendidikan dalam hal sumber belajar peserta didik. Prastowo (2014) menyebutkan bahwa modul merupakan salah satu sarana sebagai sumber belajar tipe Learning Resources by Design yaitu sumber belajar yang sengaja direncanakan dan dibuat untuk mencapai tujuan pembelajaran tertentu.

Model POE (Predict, Observe, Explain) merupakan model pembelajaran yang dikembangkan dalam pendidikan sains. Model ini dilandasi oleh teori konstruktivisme yakni dengan menggali pengetahuan yang telah diperoleh atau dimiliki peserta didik sebelumnya dan kemudian menginterpretasikannya serta mengkaitkan dengan kehidupan sehari-hari melalui tiga tahapan utama yaitu prediksi (predict), observasi (observe), dan menjelaskan hasil pengamatan (explain) (Warsono, 2012). Indrawati (2009) juga menambahkan model POE dapat menyelidiki gagasan peserta didik dan cara mereka dalam menerapkan pengetahuan pada keadaan yang sebenarnya maka peserta didik dapat membangun pengetahuan baru berdasarkan pengetahuan yang telah dimilikinya yang saling memiliki keterkaitan.

Pernyataan Warsono sesuai dengan pendapat Kearney (2004) yaitu bahwa POE memuat tiga tahapan yang meliputi prediksi, observasi, dan eksplanasi. Pada tahap prediksi, peserta didik membuat prediksi dan memperkirakan hasil pengamatan yang akan dilakukan pada tahap selanjutnya. Kemudian, peserta didik mengamati fenomena yang terjadi atau melihat eksperimen pada fase observasi. Pada tahapan terakhir, peserta didik membandingkan observasi mereka dengan prediksi dan kemudian menjelaskan observasi dengan pengetaahuan mereka sendiri. 
Widyaningrum (2013) mengemukakan bahwa dalam POE dapat meningkatkan pemahaman konsep sains peserta didik. Hal ini juga didukung oleh hasil penelitian Rahayu (2013) yang menyatakan bahwa model pembelajaran POE mampu meningkatkan ketuntasan hasil belajar peserta didik secara individual. Oleh karena itu, penggunaan berbagai sarana prasarana dan sumber belajar yang memadai sangat penting dan menunjang pembelajaran berbasis model POE (Predict, Observe, Explain).

Berdasarkan pernyataan Tanti, Aria dan Dodi (2016) modul berbasis POE menuntut peserta didik untuk berperan aktif dan memberikan pengertian bahwa aktivitas belajar berawal dari sudut pandang peserta didik bukan dari guru atau ahli. Modul berbasis POE dapat digunakan untuk merangsang peserta didik berfikir secara sains dengan mengaitkan antara konten pembelajaran dan konteks kehidupan nyata serta sesuai dengan tuntutan kurikulum 2013 karena modul berbasis POE disusun berdasarkan tahapan pembelajaran yang terdiri atas tahap prediksi, observasi, dan menjelaskan.

Sifat koligatif larutan merupakan salah satu materi dalam pembelajaran kimia yang memiliki hubungan erat dengan kehidupan sehari-hari. Adanya modul kimia yang berbasis POE pada materi sifat koligatif larutan dapat membantu peserta didik untuk melihat manfaat mempelajari materi sifat koligatif larutan dan keterpakaiannya dalam kehidupan sehari-hari sehingga pembelajaran kontekstual yang diinginkan dapat tercapai.

Berdasarkan latar belakang tersebut, maka peneliti melakukan penelitian pengembangan yang berjudul: Pengembangan Modul Kimia Berbasis Poe (Predict, Observe, And Explain) Pada Materi Sifat Koligatif Larutan Sebagai Sumber Belajar Peserta Didik Kelas XII SMA/MA.

\section{METODE PENELITIAN}

Jenis penelitian adalah penelitian pengembangan yang mengacu pada pendekatan penelitan Research and Development (R\&D). Proses pengembangan menggunakan model 4-D (Define, Design, Development, Desseminate) sebagai sebuah model desain yang dipandang sangat cocok untuk pengembangan modul kimia berbasis POE. Penelitian pengembangan model Four-D khususnya pengembangan media pembelajaran yang dilakukan para peneliti terkadang dimodifikasi dengan 
menghilangkan tahap penyebaran (dissemination) karena tujuan penelitian pengembangan media pembelajaran adalah mengembangkan media pembelajaran yang baik. Menguji kelayakan media dalam lingkup yang besar membutuhkan biaya yang cukup besar sehingga keterbatasan biaya peneliti menjadi faktor penghambat dalam melaksanakan tahap penyebaran. Menurut Trianto (2012) adapun prosedur penelitian dan pengembangan modul kimia berbasis POE telah dijelaskan pada Gambar 1.

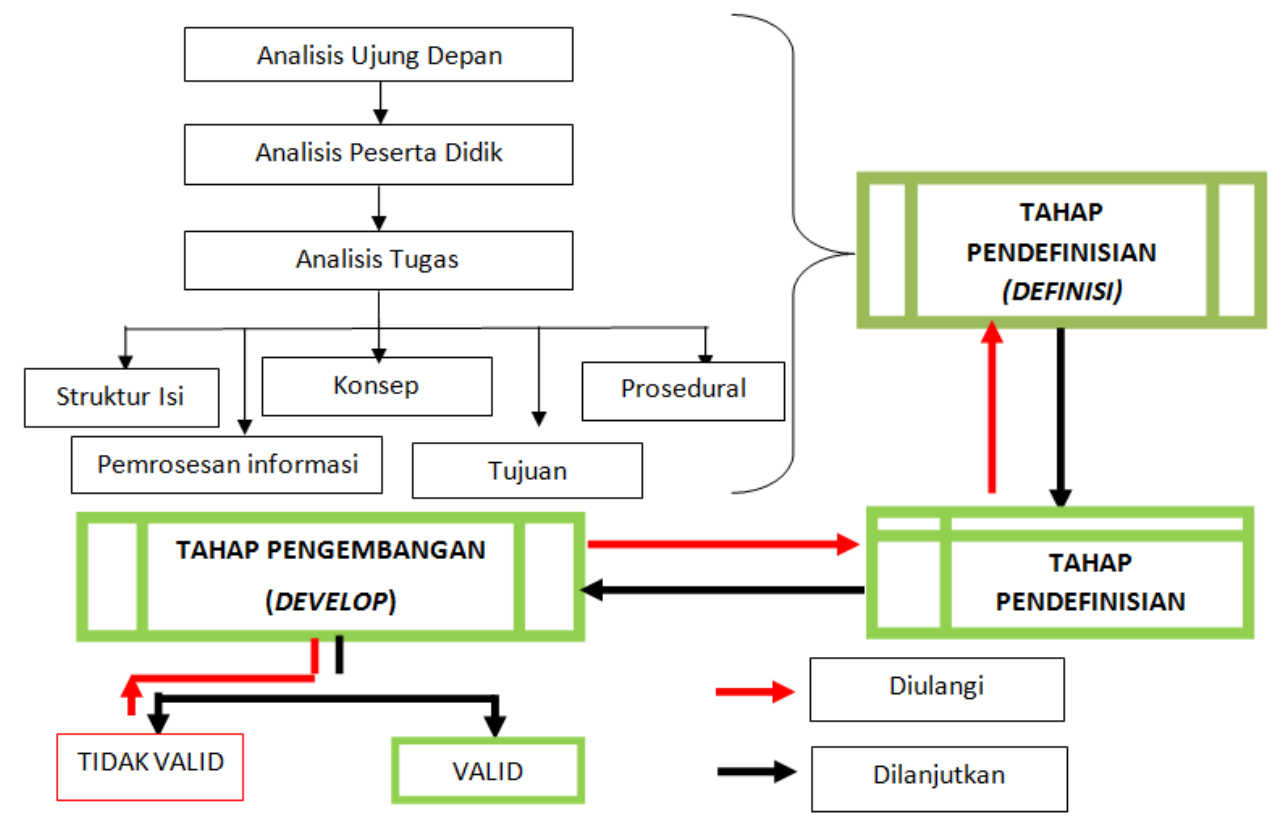

Gambar 1. Prosedur pengembangan model 4-D

Subjek penelitian yaitu dua orang validator yang terdiri dari dua orang ahli materi (Dosen Pendidikan Kimia Universitas Riau), responden peserta didik terdiri dari 10 orang peserta didik kelas XII MIA SMA N 5 Pekanbaru dan 10 orang peserta didik kelas XII MIA SMA N 8 Pekanbaru, dan responden guru terdiri dari 2 orang guru kimia kelas XII MIA SMA N 5 Pekanbaru dan 2 orang guru kimia kelas XII MIA SMA N 8 Pekanbaru. Sedangkan objek dalam penelitian ini adalah modul kimia berbasis POE sebagai sumber belajar kelas XII SMA/MA.

Modul kimia yang telah dikembangkan dinilai oleh validator untuk menguji kevalidan modul kimia dengan menggunakan lembar validasi. Lembar validasi disusun berdasarkan empat aspek yaitu aspek kelayakan isi, aspek kelayakan bahasa, aspek kelayakan kegrafikan, dan aspek kelayakan penyajian. 
Lembar validasi untuk validator disusun berdasarkan skala Likert dengan interval "valid" samai "tidak valid". Begitu juga dengan lembar tanggapan guru dan peserta didik menggunakan skala Likert

Tabel 1. Skala Penilaian Validator

\begin{tabular}{cl}
\hline Persentase & \multicolumn{1}{c}{ Keterangan } \\
\hline $80,00-100$ & Sangat Baik / Sangat Valid / Sangat Layak \\
$60,00-79,99$ & Baik / Valid / Layak \\
$50,00-59,99$ & Kurang Baik / Kurang Valid / Kurang Layak \\
$0-49,99$ & Tidak Baik \\
\hline
\end{tabular}

(Riduan, 2012)

\section{HASIL DAN PEMBAHASAN}

Penelitian pengembangan ini menghasilkan produk berupa modul kimia berbasis $P O E$ pada pokok bahasan Sifat Koligatif Larutan. Modul berbasis POE telah melewati tahap validasi oleh dosen ahli kimia dan telah diuji coba kepraktisannya oleh pengguna (guru dan peserta didik).

Rancangan awal modul yang telah disusun dikonsultasikan dengan dua orang dosen pembimbing untuk mendapat saran dan perbaikan. Revisi dari dosen pembimbing selesai, kemudian diseminarkan dan dilakukan penilaian oleh validator dan uji coba kepraktisan oleh pengguna (guru dan peserta didik).

Tahap pengembangan dilakukan setelah melewati tahap perancangan. Hasil dari tahap Pengembangan (Develop) adalah modul berbasis Predict, Observe, and Explain pada pokok bahasan Sifat Koligatif Larutan yang valid berdasarkan ahli dan praktis berdasarkan respon pengguna (guru dan peserta didik).

1) Hasil Validasi Produk

Tahap validasi bertujuan untuk memperoleh saran, masukan, dan evaluasi terhadap modul yang disusun. Validasi modul dilakukan oleh 2 orang validator, yaitu dosen Program Studi Pendidikan Kimia, Fakultas Keguruan dan Ilmu Pendidikan, Universitas Riau. Validasi dilakukan sebanyak dua kali pada masing-masing validator dan digunakan hasil validasi kedua sebagai data yang dianalisis untuk masing-masing aspek. Saat proses validasi, peneliti bersama validator melakukan diskusi untuk menyempurnakan modul yang telah dikembangkan. Saran dan masukan yang diberikan oleh masing-masing validator dijadikan acuan dalam 
melakukan perbaikan (revisi) modul sehingga menghasilkan modul Sifat Koligatif Larutan berbasis $P O E$ dengan kriteria valid.

Setiap validator menilai keseluruhan aspek yang terdapat di dalam lembar validasi. Skor tertinggi diperoleh pada aspek kelayakan bahasa dengan skor 100\%, sedangkan skor terendah diperoleh pada aspek kelayakan isi dengan skor 91,07\%.

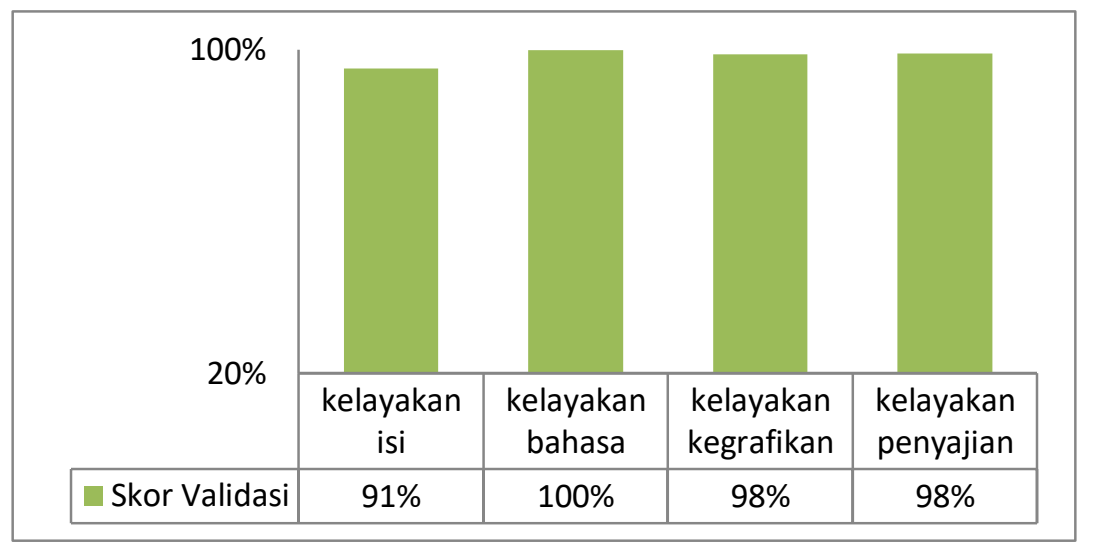

Gambar 1: Diagram Rekapitulasi Skor Rata-Rata Penilaian Aspek Validasi

a. Aspek kelayakan isi

Aspek kelayakan isi merupakan penilaian terhadap isi modul, yang memiliki 7 komponen penilaian, yaitu kelengkapan materi; keluasan materi; kedalaman materi; keakuratan konsep, prinsip, fakta, data, dan contoh; penalaran, keterkaitan, komunikasi (write and talk), serta penerapan; kemenarikan materi; keakuratan soal, gambar, diagram, ilustrasi,notasi, simbol, ikon dan acuan pustaka.

Skor rata-rata validasi aspek kelayakan isi adalah $91,07 \%$ termasuk dalam kategori valid. Terdapat 3 komponen yang mendapatkan nilai persentase rata-rata100\% (kelengkapan materi; keluasan materi; kedalaman materi), 3 komponen mendapatkan nilai persentase rata-rata87,5\% (keakuratan konsep, prinsip, fakta, data, dan contoh; keakuratan soal, gambar, diagram, ilustrasi,notasi, simbol, ikon dan acuan pustaka; Kemenarikan materi) dan 1 komponen mendapatkan nilai persentase rata-rata 75\% (penalaran, keterkaitan, komunikasi (write and talk), serta penerapan) dari validator.

Menurut penilaian validator, penyajian materi tiap pertemuan dalam modul sesuai dengan KD. Kebenaran konsep dan kesesuaian materi dengan kompetensi dasar dimaksudkan agar peserta didik tidak merasa ragu ketika 
melaksanakan pembelajaran dengan modul pembelajaran sifat koligatif larutan berdasarkan pendapat Agung Chandra Yuda (2014).

b. Aspek Kelayakan Penyajian

Penilaian terhadap aspek kelayakan penyajian memiliki terhadap 7 komponen penilaian, yaitu penilaian terhadap sistematika penyajian sesuai dengan tahapan model POE; keruntutan penyajian; memuat petunjuk penggunaan modul, glosarium, daftar pustaka, dan rangkuman; penyajian bagian pendahuluan; penyajian bagian isi; dan penyajian bagian penutup.

Skor rata-rata validasi aspek kelayakan penyajian adalah 98,21\% termasuk dalam kategori valid dengan 6 komponen mendapat skor $100 \%$ dan 1 komponen mendapat skor 87,5\%. Validator memberikan penilaian bahwa materi pembelajaran yang terdapat pada modul sesuai dengan tahapan model pembelajaran POE serta telah menyajikan rangkuman pembelajaran yang tepat.

Penyusunan modul sesuai dengan kriteria Self Instructional oleh Depdiknas yang menyatakan bahwa modul harus berisi rangkuman materi pembelajaran, instrumen penilaian, soal-soal latihan serta bahasa yang sederhana dan komunikatif sehingga mampu membelajarkan peserta didik secara mandiri

c. Aspek Kelayakan Bahasa

Aspek kelayakan bahasa merupakan penilaian terhadap penggunaan bahasa dalam modul yang memiliki 4 komponen penilaian, yaitu bahasa yang digunakan lugas; penggunaan bahasa yang komunikatif, dialogis dan interaktif.; kesesuaian dengan tingkat perkembangan peserta didik, keruntutan dan keterpaduan alur pikir ; dan penggunaan istilah, simbol, atau ikon. Skor rata-rata penilaian oleh validator pada aspek ini adalah $100 \%$ dengan kategori valid. Validator memberikan penilaian bahwa struktur kalimat dalam modul tepat, efektif, dan istilah yang digunakan sudah baku serta modul telah sesuai dengan kriteria user friendly artinya memuat instruksi dan paparan informasi yang bersifat membantu dan bersahabat dengan pemakainya.

d. Aspek Kelayakan Kegrafikan

Aspek kelayakan kegrafikan merupakan penilaian terhadap ukuran modul; tata letak modul; warna dalam modul; penempatan dalam modul; spasi dalam modul; dan penggunaan variasi dalam modul. 
Validator memberikan penilaian terhadap aspek kelayakan kegrafikan dengan skor rata-rata 97,91\% dengan kategori valid. Validator menilai bahwa ilustrasi/gambar yang disajikan dalam modul jelas dan berhubungan dengan konsep. Modul yang dikembangkan menggunakan gambar berwarna dan menarik. Penyajian modul yang berwarna bertujuan agar modul mempunyai daya tarik untuk dibaca. Penggunaan warna pada penyajian modul selaras dengan pendapat Ashyar, untuk membangun kemenarikan pada media bahkan dapat mempertinggi realisme dan menciptakan respon emosional diperlukan warna.

2) Hasil Uji Coba Kepraktisan

a. Respon Guru

Modul diuji kepraktisan penggunaannya oleh 2 orang guru bidang studi kimia dari SMAN 5 Pekanbaru dan 2 orang guru bidang studi kimia dari SMA 8 Pekanbaru. Guru yang memberikan respon terlebih dahulu diberikan modul untuk dipelajari. Setelah mempelajari modul secara keseluruhan, guru memberikan penilaian terhadap modul dengan menggunakan angket respon guru

Respon guru menggunakan skala Likert berbentuk pilihan ganda dengan 5 pilihan. Pernyataan paling positif mendapatkan skor tertinggi, seterusnya hingga pernyataan paling negatif mendapatkan skor terendah. Skala Likert digunakan pada kuesioner respon guru agar penilaian yang diberikan lebih detail. Skor rata-rata respon guru terhadap modul adalah 93,667\% artinya dapat digunakan tanpa revisi.

b. Respon Peserta Didik

Uji coba terbatas pada peserta didik dilakukan untuk menilai aspek kepraktisan penggunaan modul kimia berbasis POE yang dikembangkan. Uji coba dilakukan terhadap 10 orang peserta didik XII MIA SMAN 5 Pekanbaru dan 10 orang peserta didik XII MIA SMAN 8 Pekanbaru. Peserta didik yang menjadi responden adalah peserta didik yang telah mempelajari pokok bahasan Sifat Koligatif Larutan.

Uji coba dilakukan dengan terlebih dahulu melakukan sosialisasi mengenai modul dan strategi Predict, Observe, and Explain kepada peserta didik. Setiap peserta didik diberikan satu eksamplar modul untuk dibaca dan 
dipelajari. Peserta didik diberikan kuesioner respon untuk melakukan penilaian terhadap modul, setelah membaca modul secara keseluruhan.

Persentase rata-rata tanggapan peserta didik terhadap modul adalah $89,53 \%$ artinya modul dapat digunakan dengan baik.

\section{KESIMPULAN}

Berdasarkan hasil penelitian dan pembahasan dapat disimpulkan bahwa modul kimia berbasis POE (Predict, Observe, and Explain) pada materi sifat koligatif larutan sebagai sumber belajar peserta didik kelas XII SMA/MA yang telah dikembangkan valid berdasarkan aspek kelayakan isi, kebahasaan, penyajian, dan kegrafisan dengan persentase rata-rata validasi 96,7975\%, mendapat skor rata-rata 93,66\% dari guru yang dapat digunakan tanpa revisi dan mendapat skor rata-rata 89,53\% dari peserta didik yang artinya dapat digunakan dengan baik.

\section{DAFTAR PUSTAKA}

Indrawati, 2009, Pembelajaran Aktif, Kreatif, Efektif, dan Menyenangkan untuk Guru, PPPTK IPA, Bandung.

Kearney, 2004, Classroom Use of Multimedia-Supported Predict-Observe-Explain Tasks in a Social Constructivist Learning Enviroment, Kluwer Academic Publishers, Research in Science Education Netherlands

Prastowo, A., 2014, Pengembangan Bahan Ajar Temati, DIVA Press Kencana Prenada Media Group, Jakarta

Rahayu, 2013, Pengembangan Perangkat Pembelajaran POE Berbantuan Media, Innovatif Journal of Curriculum and Educational Technology, 6 (1)

Riduan, 2012, Skala Pengukuran Variabel-variabel Penelitian, Alfabeta, Bandung

Tanti, A. dan Dodi., 2016, Pengembangan Modul Berbasis POE pada Materi Usaha dan Energi, Universitas Muhammadiyah Metro

Trianto, 2012, Mendesain Model Pembelajaran Inovatif-Progresif, Kencana, Jakarta

Warsono, 2012, Peningkatan Hasil Belajar Siswa Melalui Pendekatan Keterampilan Sains Berorientasi Predict, Observe and Explain, Jurnal Inovasi Pendidikan Kimia. 3 (1) 
Widyaningrum, 2013, Pengembangan Modul Berorientasi POE Berwawasan Lingkungan Pada Materi Pencemaran untuk Meningkatkan Hasil Belajar Peserta Didik, Jurnal Bioedukasi, 6 